\title{
ÁcIdOS E BASES NO COTIDIANO: UMA PROPOSTA DE EXPERIMENTO INVESTIGATIVO PARA O ENSINO MÉDIO
}

\author{
ACIDS AND BASES IN THE EVERYDAY LIFE: A PROPOSAL OF \\ INVESTIGATIVE EXPERIMENT FOR HIGH SCHOOL
}

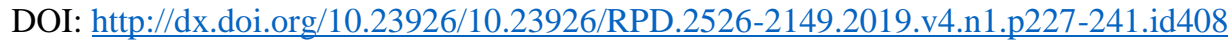

\section{Paula Cavalcante Monteiro \\ Doutora em Ensino de \\ Ciências e Matemática \\ (UEM) \\ Professora Adjunta (UTFPR) \\ paulamonteiro@utfpr.edu.br}

\section{Maria Aparecida \\ Rodrigues}

Doutora em Química

(UNICAMP)

Professora Associada

(UEM/PCM)

aparecidar@gmail.com

\section{Ourides Santin Filho \\ Doutor em Ciências (USP) \\ Professor Associado \\ (UEM/PCM) \\ osantin@uem.br}

\section{Michel Corci Batista}

Doutor em Ensino de

Ciências e Matemática

(UEM)

Professor Adjunto

(UTFPR/PCM)

michel@utfpr.edu.br
Resumo: O presente trabalho teve como objetivo investigar as potencialidades didáticas de uma atividade experimental investigativa sobre ácidos e bases. A atividade foi desenvolvida em uma turma do segundo ano do Ensino Médio. A intervenção pedagógica envolveu reflexão sobre como reconhecer produtos ácidos e alcalinos presentes no dia a dia, a leitura e discussão de um texto sobre origem e características físicas e químicas de substâncias ácidas e alcalinas, realização do experimento utilizando várias substâncias cotidianas de caráter ácido e básico, bem como uma escala de $\mathrm{pH}$ preparada com extrato de repolho roxo e soluções aquosas de ácido clorídrico e hidróxido de sódio. Após o experimento, mediante discussão, os alunos, em grupos, responderam questões com vistas à análise dos dados observados. Na sequência responderam individualmente a uma questão que tinha o intuito de verificar a aplicação do conhecimento. Os resultados evidenciam que os alunos tiveram boa compreensão acerca dos conhecimentos desenvolvidos, o que nos leva a concluir que experimentos investigativos, como o discutido aqui, favorecem a aprendizagem de conhecimentos científicos.

Palavras-Chave: Ensino de Química; ácidos e bases; experimentação.

\begin{abstract}
The aim of this work was to investigate the didactic potential of an experiment about acids and bases. The experiment was developed with High School sophomores. The pedagogical intervention reflected on how to recognize acid and alkaline products present in everyday life, the reading and discussion of a text about the origin and physical and chemical characteristics of acid and alkaline substances, carrying out an experiment using various daily life substances of acidic and basic character as well as a $\mathrm{pH}$ scale prepared with extract of purple cabbage and aqueous solutions of hydrochloric acid and sodium hydroxide. After the experiment, during group discussions, the students answered questions in order to analyze the observed data. Afterwards, they answered a question individually in order to verify the application of knowledge. The results demonstrated that the students had a good understanding of the knowledge developed, which leads us to conclude that research experiments, such as the one discussed here, promotes the learning of scientific knowledge.
\end{abstract}

Keywords: Chemistry Teaching; acids and bases; experimentation. 


\section{INTRODUÇÃO}

As atividades experimentais no ensino de Química são consideradas, de maneira geral pelos professores, um poderoso recurso didático capaz de melhorar o entendimento de conteúdos químicos. Silva e Zanon (2000, p. 126) confirmam essa ideia, mencionando que, em nossas escolas, "prevalece essa visão simplista de que a experimentação contribui automaticamente para a melhora das aulas de ciências e para a aquisição do conhecimento científico por parte dos alunos". Essa maneira reducionista e sem reflexão a respeito das atividades experimentais nas aulas de Ciências tem sido a preocupação de vários autores: Carvalho (2013); Kasseboehmer et al. (2015); Santana e Silva (2014) e Suart (2014).

Durante o ensino básico e até mesmo nas disciplinas introdutórias da graduação, as aulas experimentais muitas vezes são desenvolvidas pelo professor como tentativa de comprovar teorias ou motivar os alunos à aprendizagem. É relevante considerar o fato de que, ao reproduzir um roteiro com resultados previamente conhecidos, os alunos nem sempre compreendem claramente os objetivos propostos pelo experimento. Nesta concepção, "o conhecimento científico é obtido daquilo que se observa, pois, a observação é a fonte e a função do conhecimento, por meio da aplicação do método científico" (ROSITO, 2000, p. 200).

Nas aulas experimentais com abordagem investigativa, que se contrapõem ao exposto acima, ao aluno é apresentada uma situação problema que irá instigá-lo na busca pela sua solução. Assim, "é o problema proposto que irá desencadear o raciocínio dos alunos, bem como a coragem de expor seus pensamentos e suas argumentações" (CARVALHO, 2018, p. 767). Dessa maneira, o papel do professor passa a ser o de orientador, criando situações em sala de aula, no sentido de encorajar os alunos a participarem ativamente na busca de soluções.

Acreditamos que, nessa perspectiva, as aulas experimentais com abordagem investigativa "podem possibilitar a compreensão da natureza da ciência e dos seus conceitos, bem como auxiliar no desenvolvimento de atitudes científicas, contribuindo para despertar no aluno o interesse pela Ciência” (MONTEIRO, et al., 2017, p. 2),

Para que isso ocorra, é necessário conduzir as aulas de laboratório de maneira oposta às tradicionais. Isso significa que o professor deve considerar a importância de colocar os alunos frente a situações-problema adequadas, propiciando a construção do próprio conhecimento (FERREIRA; HARTWIG; OLIVEIRA, 2010, p.101).

Entendemos como oposição ao tradicionalismo nas aulas de laboratório, o fato de o professor abandonar o roteiro seguido passo a passo e promover uma discussão sobre os resultados encontrados, sejam eles errados ou certos (MONTEIRO, 2018). Dessa forma, os alunos podem desenvolver uma visão mais esclarecida da Ciência. 
Assim, nosso trabalho teve como objetivo investigar, junto a uma turma do primeiro ano do Ensino Médio (EM) de uma escola pública de Maringá-PR, o potencial de uma atividade experimental investigativa para abordar o tema ácidos e bases.

Apoiando-nos em autores que discutem a experimentação investigativa, discutimos a seguir sua importância para o ensino de química. Apresentamos os procedimentos metodológicos adotados nesse estudo e discutimos seus resultados. Por fim, trazemos as considerações, destacando as contribuições da experimentação investigativa no ensino de conhecimentos científicos.

\section{REFERENCIAL TEÓRICO}

Não se tem mais dúvidas de que as atividades experimentais são recursos importantes para a aprendizagem em Ciências e as mesmas envolvem muito mais os alunos do que as aulas expositivas. A experimentação é uma ferramenta capaz de tornar as aulas mais próximas da realidade do aluno, sendo uma maneira de abandonar as aulas clássicas focada no formalismo matemático (SILVA; 2017). Porém, a pouca utilização desse recurso por parte dos professores é justificada, por exemplo, pelo excesso de alunos por turma, pela falta de laboratório e materiais adequados, bem como a imaturidade dos alunos para realizarem atividades desta natureza.

Conforme os estudos de Silva e Zanon (2000, p. 126), entre os professores impera a "visão simplista de que a experimentação contribui automaticamente para a melhora das aulas de ciências e para a aquisição do conhecimento científico por parte dos alunos”. Para as referidas autoras, as aulas experimentais não asseguram, por si só, o estabelecimento de relações entre a teoria e a prática. No entanto, os experimentos possuem a potencialidade de "ajudar os alunos a aprender por meio do estabelecimento de inter-relações entre os saberes teóricos e práticos inerentes aos processos do conhecimento escolar em ciências" (SILVA; ZANON, 2000, p. 134).

Rosito (2000, p. 197) concorda com as ideias das autoras acima ao mencionar que:

[...] as atividades experimentais não devem ser desvinculadas das aulas teóricas, das discussões em grupo e de outras formas de aprender. O que foi exposto em aula e o que foi obtido no laboratório precisa se constituir como algo que se complementa. Às vezes, isto pode parecer difícil, mas esta unidade é fundamental, pois as atividades experimentais realizadas sem integração com uma fundamentação teórica não passam de ativismo.

Em consonância com o exposto anteriormente, Costa (2000, p. 97) argumenta que "a atividade experimental é mais uma oportunidade para romper com o senso comum e, portanto, 
seus resultados não podem conduzir ao óbvio, simplesmente, aquilo que os alunos já esperavam". Para a mesma autora, o professor, no laboratório, deve procurar defender seus alunos da sedução da facilidade, questionando-lhes acerca de possibilidade de resultados antes de fornecer-lhes todas as respostas, ou seja, deve-se manter uma dúvida.

\begin{abstract}
A partir do momento em que o aluno passa a desenvolver uma atividade práticaexperimental, proposições são feitas e, diante de uma dada situação problema, ele poderá identificar possíveis estratégias para resolvê-la; selecionar e utilizar instrumentos adequados de verificação; propor modelos explicativos; estabelecer relações entre fenômenos; analisar e interpretar os resultados (PAVÃO; FREITAS, 2011, p. 77).
\end{abstract}

Uma atividade experimental, com as características relacionadas por Pavão e Freitas (2011), configura-se como uma experimentação investigativa e exige a participação ativa do aluno. De acordo com Sasseron e Machado (2017), esse tipo de atividade exige do aluno ações e atitudes que permitam mais do que o simples fazer; tais ações e atitudes devem permitir também o compreender, o que consideramos essencial para uma aula de ciências.

Entendemos que, dessa forma, os alunos poderão desenvolver as competências necessárias para resolver os problemas surgidos no seu dia a dia.

As atividades experimentais investigativas partem de uma situação problema, de interesse do aluno a fim de que este se motive e veja necessidade em aprender o conteúdo a ser desenvolvido. Este problema, no entanto, não deve ser de difícil resolução, de modo que o estudante desista de investigá-lo (SUART, 2014, p. 74).

Concordamos com a autora quanto ao problema proposto não ser muito complexo. $\mathrm{O}$ mesmo deve manter o interesse do aluno em investigar, ou seja, persistir em sua resolução, pois assim chegará à construção do seu próprio conhecimento. Um problema adequado:

- dá condições para os alunos resolverem e explicarem o fenômeno envolvido no mesmo

- dá condições para que as hipóteses levantadas pelos alunos levem a determinar as variáveis do mesmo;

- dá condições para os alunos relacionarem o que aprenderam com o mundo em que vivem;

- dá condições para que os conhecimentos aprendidos sejam utilizados em outras disciplinas do conteúdo escolar (CARVALHO, 2018, p. 771).

Ainda seguindo o pensamento da respectiva autora, o Ensino Investigativo deve propor não somente verificar se os alunos aprendem os conteúdos programáticos, mas se faz importante que "eles saibam falar, argumentar, ler e escrever sobre esse conteúdo" (CARVALHO, 2018, p. 766). 
Segundo Gonçalves e Brito (2014), para os pesquisadores envolvidos com estudos sobre atividades investigativas, é consensual a ideia de que o professor deve partir da apresentação de um problema, podendo este ser elaborado por ele ou pelos alunos. No entanto, os mesmos devem reconhecer que a situação proposta se caracteriza como um problema e não de um exercício que se utiliza de um dispositivo mecânico para resolvê-lo.

Elaborar uma atividade com essas características não é uma tarefa fácil; exige-se que o professor tenha clareza de seus objetivos pedagógicos e que "faça perguntas, proponha problemas e questione comentários e informações trazidos pelos estudantes, tendo como intuito o trabalho investigativo com o tema da aula" (SASSERON, 2013, p. 43). A autora afirma que o professor precisa saber perguntar, pois uma boa pergunta depende do conhecimento que se tem sobre o tema e também da atenção que deve ser dada ao que os alunos dizem. Esse cuidado com as informações que os alunos trazem é importante, pois o professor precisa explorá-las para confrontá-las com a ideia exposta. Para Oliveira (2013, p. 64) é preciso que o professor seja "capaz de transformar a linguagem do cotidiano, trazida pelos alunos, em linguagem científica".

Para que professores atuantes reflitam sobre os aspectos pedagógicos das atividades experimentais, no sentido de romper com a ideia simplista de que a experimentação promove incondicionalmente a aprendizagem, "é preciso desenvolver no processo formativo atividades que favoreçam a apropriação de conhecimentos contemporâneos em torno das atividades experimentais [...]” (GONÇALVES; BRITO, 2014, p. 32).

\section{Metodologia}

Neste trabalho, de natureza qualitativa,, buscamos analisar o potencial de uma proposta experimental investigativa sobre ácidos e bases, que foi desenvolvida com 22 alunos do EM, com faixa etária entre 15 e 17 anos de uma escola pública de Maringá-PR.

Para Bogdan e Biklen (1994), na investigação qualitativa, a fonte de dados consiste no próprio ambiente em que está inserido o objeto/sujeito do estudo e, além disso, o pesquisador tem um papel fundamental como instrumento de coleta durante todo o trabalho em campo.

Destacamos que esse trabalho é um desdobramento de uma pesquisa mais ampla, envolvendo a temática Experimentação Investigativa (EI), na qual dentre as várias etapas desenvolvidas, foi realizado um curso de 30 horas sobre experimentação investigativa. Como atividade final nesse curso, seus participantes deveriam propor um experimento com características investigativas para ser desenvolvido no EM. Neste sentido, discutimos aqui 
apenas os resultados da implementação de uma das propostas experimentais investigativas elaboradas no contexto da pesquisa. No Quadro 1 apresentamos a proposta experimental elaborada.

Quadro 1 - Descrição da proposta experimental investigativa elaborada

FICHA TÉCNICA: Atividade prática sobre ácidos e bases

\begin{tabular}{|l|l|l|}
\hline \hline PÚBLICO ALVO & $\begin{array}{l}\text { Alunos do } 2^{\circ} \text { ano do } \\
\text { Ensino Médio } \\
\text { Público e Estadual. }\end{array}$ & DURAÇÃO: 03 aulas de 50 minutos. \\
\hline \hline $\begin{array}{l}\text { OBJETIVO } \\
\text { GERAL }\end{array}$ & Refletir com os alunos as características dos ácidos e bases. \\
\hline \hline PRÉ REQUISITROS & $\bullet \quad$ Noções básicas de ácidos e bases. \\
\hline \hline
\end{tabular}

\section{CONTEXTUALIZAÇÃ̃O} PARA A ATIVIDADE
Percebemos quando uma fruta está madura por conta da coloração de sua pele e o sabor de seu fruto. Isso ocorre porque as substâncias responsáveis pela coloração de flores e frutos são sensíveis à variação da acidez do solo. Nas frutas, temos como exemplos dessa variação a banana verde que "trava" a língua devido à adstringência, característica de uma base, e a laranja verde, que é azeda, característica de ácidos. No caso das flores, a hortênsia em solo ácido produz flores azuis, já em solos básicos suas flores são cor-de-rosa. A intensidade dessas cores depende do teor de acidez ou basicidade do solo.

Frequentemente ácidos e bases são lembrados como substâncias químicas prejudiciais tanto ao homem quanto ao meio ambiente. No entanto, ácidos e bases, quando se combinam produzem água e compostos chamados sais. As reações entre ácidos e bases podem ser fortes, e o resultado é uma produção rápida de gases.

Alguns tipos de alimentos costumam provocar azia ou queimação no estômago; são exemplos: frutas cítricas, cafeína, chocolate e bebidas alcoólicas. Estas podem causar a gastrite, que é uma inflamação da parede do estômago e acontece quando a acidez aumenta. Indivíduos com gastrite possuem o $\mathrm{pH}$ do suco gástrico menor que 1,5. O suco gástrico é basicamente formado por água, ácido clorídrico e enzimas digestivas.

Essa medida do grau de acidez é feita por meio do potencial hidrogeniônico (pH), ou seja, é a medida do teor de íons $\mathrm{H}_{3} \mathrm{O}^{+}$livres por unidade de volume. O pH é a escala que vai de 0 a 14, em que 0 é o mais ácido e 14 o mais básico. O pH da água neutra é 7 . Esse é o método mais eficaz e seguros de identificar ácidos e bases do que o paladar.

As substâncias classificadas como ácidas, do latim "acidus" que significa "azedo", reagem com bicarbonatos e carbonatos liberando gás carbônico; reagem com certos metais (ferro, zinco, etc), liberando hidrogênio $\left(\mathrm{H}_{2}\right)$ e neutralizam soluções básicas.

A partir do século XVI, as substâncias alcalinas (do árabe "cinzas vegetais") passaram a ser também denominadas de bases. As soluções 


\begin{tabular}{|c|c|}
\hline & $\begin{array}{l}\text { aquosas de bases apresentam geralmente sensação de escorregadia ao } \\
\text { contato e neutralizam ácidos. }\end{array}$ \\
\hline $\begin{array}{l}\text { SITUAÇÃO } \\
\text { PROBLEMA }\end{array}$ & $\begin{array}{l}\text { Como você pode reconhecer produtos ácidos e alcalinos presentes no seu } \\
\text { dia a dia? }\end{array}$ \\
\hline $\begin{array}{l}\text { PROCEDIMENTO } \\
\text { EXPERIMENTAL }\end{array}$ & 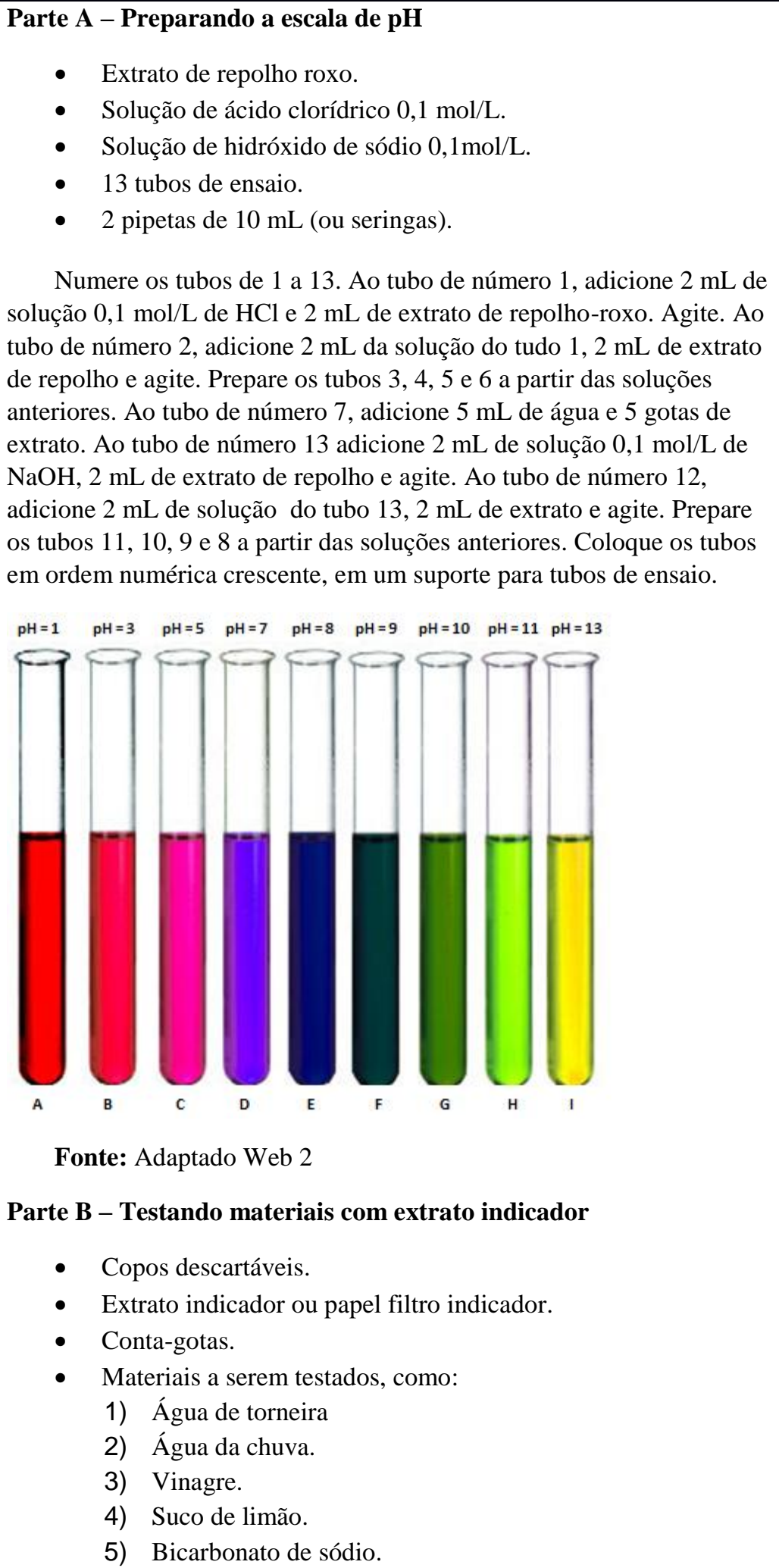 \\
\hline
\end{tabular}




\begin{tabular}{|c|c|c|c|c|c|c|c|c|c|c|c|c|}
\hline & $\begin{array}{r}\text { 6) Limp } \\
\text { 7) Deter } \\
\text { 8) Refrig } \\
\text { 9) Hidró } \\
\text { 10) Leite } \\
\text { Numere os } \\
\text { materiais a serem te } \\
\text { Observe e anote no } \\
\text { gotas de extrato de } \\
\text { cada solução. Comp } \\
\text { E anote a cor semel }\end{array}$ & $\begin{array}{l}\text { lo. } \\
\text { te. } \\
\text { de } \\
\text { agn } \\
\text { se } \\
\text { duac } \\
\text { ho- } \\
\text { is ce }\end{array}$ & sio. & $\begin{array}{l}\text { inio } \\
\text { one } \\
\text { cen } \\
\text { cor } \\
\text { e a\& } \\
\text { ina } \\
\text { or } t\end{array}$ & 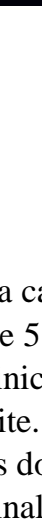 & 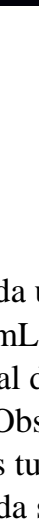 & 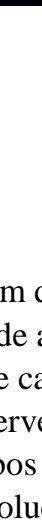 & $\begin{array}{l} \\
\text { leles } \\
\text { gua } \\
\text { da s } \\
\text { e a } \\
\text { com } \\
\text { ão. }\end{array}$ & $\begin{array}{l} \\
\\
5 \mathrm{~m} \\
\mathrm{e} \mathrm{ag} \\
\text { oluç } \\
\text { lote } \\
\text { os t }\end{array}$ & L d & $\begin{array}{l} \\
\text { um } \\
\text { em. } \\
\text { dici } \\
\text { din } \\
\text { da e }\end{array}$ & $\begin{array}{l}\text { dos } \\
\text { dne } 5 \\
\text { scala. } \\
\text { se }\end{array}$ \\
\hline & Material & 1 & 2 & 3 & 4 & 5 & 6 & 7 & 8 & 9 & 10 & \\
\hline & Cor Inicial & & & & & & & & & & & \\
\hline & Cor Final & & & & & & & & & & & \\
\hline $\begin{array}{l}\text { QUESTÕES PARA } \\
\text { ANÁLISE DOS DADOS }\end{array}$ & $\begin{array}{l}\text { 1. Classifique o } \\
\text { básicos). } \\
\text { 2. Comente a fr } \\
\text { 3. Com base no } \\
\text { a água da chı } \\
\text { 4. Com base er } \\
\text { indicador, u } \\
\text { comer uma s }\end{array}$ & $\begin{array}{l}\text { teri } \\
\text { ácic } \\
\text { rim } \\
\text { Exp } \\
\text { as o }\end{array}$ & iqu & $\begin{array}{l}\text { esta } \\
\text { oda } \\
\text { hou } \\
\text { jaçô } \\
\text { ue }\end{array}$ & . & tan & cia & $\begin{array}{l}\text { grt } \\
\text { que } \\
\text { da } \\
\text { o do } \\
\text { nter }\end{array}$ & $\begin{array}{l}\text { pos } \\
\text { orr } \\
\text { figua } \\
\text { col } \\
\text { hent } \\
\text { re? }\end{array}$ & $\begin{array}{l}\text { (os } \\
\text { i”. } \\
\text { de } \\
\text { npo } \\
\text { e de }\end{array}$ & $\begin{array}{l}\text { ácide } \\
\text { ornei } \\
\text { tame } \\
\text { azi }\end{array}$ & $\begin{array}{l}\text { s e os } \\
\text { ra com } \\
\text { nto do } \\
\text { pode }\end{array}$ \\
\hline $\begin{array}{l}\text { APLICAÇÃO DO } \\
\text { CONHECIMENTO }\end{array}$ & $\begin{array}{l}\text { Urtiga é o nome g } \\
\text { Urticáceas, cujas } \mathrm{f} \\
\text { ácido fórmico }\left(\mathrm{H}_{2}\right. \\
\text { Dos produtos testa } \\
\text { diminuir essa irrit }\end{array}$ & que & & $\begin{array}{l}\text { a di } \\
\text { erta } \\
\text { cor } \\
\text { dim } \\
\text { ue s }\end{array}$ & $C r$ & $15 \mathrm{p}$ & & $\begin{array}{l}\text { Is d } \\
\text { ino } \\
\text { ele } \\
\text { cê }\end{array}$ & $\begin{array}{l}\text { fan } \\
\text { os } \\
\text { proc } \\
\text { ode }\end{array}$ & $\begin{array}{l}\text { ília } \\
\text { qua } \\
\text { uz i } \\
\text { cia } \mathrm{u}\end{array}$ & $\begin{array}{l}\text { das } \\
\text { s libe } \\
\text { ritaç } \\
\text { tiliza }\end{array}$ & $\begin{array}{l}\text { ram } \\
\text { ão. } \\
\text { r para }\end{array}$ \\
\hline REFERÊNCIAS & $\begin{array}{l}\text { Santos, W. L (Coor } \\
\text { Nova Geração, } 200 \\
\text { Santos, W. L (Coor } \\
\text { Paulo: AJS, } 2013 \text {. } \\
\text { WEB 1: https://edu } \\
\text { definicoes-de-arrhe } \\
\text { WEB 2: https://ww } \\
\text { quimica/indicador- }\end{array}$ & Quír & & $\begin{array}{l}\text { \& } \\
\text { noor } \\
\text { n.br } \\
\text {-lov } \\
\text { lim }\end{array}$ & & & & $\begin{array}{l}\text { ol. } \\
\text { Ci } \\
\text { quir } \\
\text { tem } \\
\text { rim }\end{array}$ & $\begin{array}{l}\text { Únic } \\
\text { lad } \\
\text { iica } \\
\text { ento }\end{array}$ & $\begin{array}{l}\mathrm{O}, \mathrm{S} \\
\mathrm{V} \\
\text { acic } \\
\mathrm{S}-\end{array}$ & 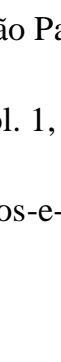 & $\begin{array}{l}\text { ulo: } \\
\text { São } \\
\text { bases- }\end{array}$ \\
\hline
\end{tabular}

Fonte: Os autores (2019).

O desenvolvimento do material elaborado (Experimento Investigativo) se deu em três aulas dialogadas sobre a temática ácidos e bases. Na primeira etapa, os alunos foram convidados a refletir sobre a questão: Como você pode reconhecer produtos ácidos e alcalinos presente no seu dia a dia? Para desenvolver o conhecimento sobre o tema, os alunos receberam um texto elaborado pelos autores, que foi lido e discutido em conjunto. 
A segunda etapa caracterizou-se por uma atividade experimental investigativa sobre ácidos e bases. Nesta, os alunos realizaram, em pequenos grupos, o experimento descrito no quadro 1, utilizando como indicador o extrato de repolho roxo e também uma escala de $\mathrm{pH}$, ambos preparados pelos pesquisadores. A escala de $\mathrm{pH}$ foi preparada com base em Santos e Mól (2005).

Após realização do experimento e preenchimento da tabela contida no roteiro experimental, com suas observações, conforme material já mencionado, foi promovida uma discussão para refletir as questões para análise dos dados.

$\mathrm{Na}$ terceira etapa, os alunos responderam a uma questão referente à aplicação do conhecimento.

Urtiga é o nome genérico dado a diversas plantas da família das Urticáceas, cujas folhas são cobertas por pelos finos, os quais liberam ácido fórmico $\left(\mathrm{H}_{2} \mathrm{CO}_{2}\right)$ que, em contato com a pele produz irritação. Dos produtos testados no procedimento qual você poderia utilizar para diminuir essa irritação? Justifique sua escolha.

O conteúdo das respostas referentes a esta questão é o objeto de discussão desse artigo, assim nosso instrumento de coleta de dados constituiu-se de uma questão aberta, na qual o aluno poderia apresentar uma resposta com base na sua concepção sobre o fenômeno estudado. Pensamos numa questão desse tipo para dar liberdade ao aluno e evitar ao máximo interferir de alguma forma no direcionamento de sua resposta. Nesse estudo, utilizamos a Análise Textual Discursiva (ATD) os pressupostos de Moraes e Galiazzi (2007), para associar os dados obtidos com os objetivos da pesquisa. As categorias essenciais para a análise foram estabelecidas a priori e evidenciaram elementos fundamentais de análise, contribuindo assim para verificar se o experimento investigativo desenvolvido promoveu a compreensão dos alunos acerca de conhecimentos sobre ácidos e bases. As categorias estabelecidas nesse estudo para a análise dos dados estão apresentadas no quadro 2.

Quadro 2 - Categorias estabelecidas por meio da ATD

\begin{tabular}{|c|l|}
\hline Categoria & \multicolumn{1}{|c|}{ Descrição } \\
\hline 1 & Justificativa com base em conhecimentos químicos. \\
\hline 2 & Justificativa com base em conhecimento do senso comum. \\
\hline 3 & Sem Justificativas e/ou Justificativas incoerentes. \\
\hline
\end{tabular}

Fonte: Os autores 2019.

A seguir encaminhamos uma discussão tomando como referência essas categorias. 


\section{Resultados}

Apresentamos a seguir somente os resultados referentes às análises da questão de comunicação dos resultados do material elaborado. Vale ressaltar que essa questão foi respondida individualmente após a realização do experimento e discussão da atividade de análise dos dados com todos os participantes da pesquisa.

Percebemos que, de maneira geral, os alunos tiveram uma boa compreensão dos conhecimentos desenvolvidos, pois todos escolheram uma substância com caráter básico (leite de "magnésio" e bicarbonato de sódio) ou levemente básico (água de torneira), numa tentativa de aliviar a coceira causada pelo ácido fórmico das folhas de urtiga.

Para associar as justificativas dos alunos à categoria 1 (justificativas com base em conhecimentos químicos), levamos em consideração o fato de os sujeitos evidenciarem o conceito de "neutralização" e "base" para justificar o alívio para a coceira. No quadro 3 a seguir estão as descrições dessas justificativas.

Quadro 3 - Categoria 1: Justificativas com base em conhecimentos químicos

\begin{tabular}{|c|c|}
\hline Sujeitos & Descrição \\
\hline $\mathrm{S} 1$ & $\begin{array}{l}\text { Água de torneira, porque além de ser uma base para neutralizar o ácido, pode acalmar } \\
\text { mais e diminuir a irritação, refrescar mais. }\end{array}$ \\
\hline $\mathrm{S} 2$ & $\begin{array}{l}\text { Para neutralizar o ácido iria usar uma base que no caso seria água de torneira, pois a água } \\
\text { iria relaxar o local irritado. }\end{array}$ \\
\hline S5 & $\begin{array}{l}\text { Na minha opinião é o leite de magnésio, pois é uma base e com a mistura desse ácido com } \\
\text { a base diminuiria a irritação, acalmando o local. }\end{array}$ \\
\hline S8 & $\begin{array}{l}\text { Leite de magnésio pois ele é uma base e ele vai controlar o ácido, e vai regular e } \\
\text { neutralizar. }\end{array}$ \\
\hline S9 & $\begin{array}{l}\text { Leite de magnésio, porque quando colocado em um indicador, este apresenta uma } \\
\text { coloração verde clara, classificado como uma base. Uma base neutraliza um ácido. }\end{array}$ \\
\hline S10 & $\begin{array}{l}\text { Bicarbonato, por neutralizar e é uma coisa que eu teria em casa, então eu misturaria o } \\
\text { bicarbonato com água e passaria na pele. }\end{array}$ \\
\hline S17 & $\begin{array}{l}\text { O leite de magnésio, pois ele é uma base então ele ajuda a aliviar a irritação que o ácido } \\
\text { da planta deixou. }\end{array}$ \\
\hline S19 & $\begin{array}{l}\text { Bicarbonato de sódio porque é uma base e pode ser usada para neutralizar o efeito do } \\
\text { ácido. }\end{array}$ \\
\hline $\mathrm{S} 20$ & $\begin{array}{l}\text { Eu usaria leite de magnésio pois com uma base neutralizaria esse ácido e diminuiria a } \\
\text { irritação. }\end{array}$ \\
\hline $\mathrm{S} 21$ & $\begin{array}{l}\text { Utilizaria leite de magnésio, porque ele é uma base e quando entra em contato com um } \\
\text { ácido neutraliza ele. }\end{array}$ \\
\hline $\mathrm{S} 22$ & $\begin{array}{l}\text { Eu escolheria uma base e essa seria no caso a água da torneira pois a água acredito eu que } \\
\text { neutraliza todo e qualquer irritação provocada pelos ácidos e todas as demais substâncias. }\end{array}$ \\
\hline
\end{tabular}

Fonte: Os autores 2019. 
Observamos que, dos onze sujeitos (50\% da nossa amostra) nove utilizaram a palavra "neutralizar" ou a deixaram implícita em suas justificativas. Enquanto que, os sujeitos S5 e S17 se referiram ao conceito de "base" para justificar suas respostas. Tais fatos nos permitem inferir, em consonância com Sasseron e Machado (2017), que os alunos não só desenvolveram a atividade experimental, mas também compreenderam o conceito que fundamentava a atividade.

Podemos ainda dizer que a atividade proposta permitiu aos alunos o ato de ler, argumentar e escrever sobre o assunto discutido, o que, de acordo com Carvalho (2018), são habilidades importantes proporcionadas por uma atividade investigativa. Alguns dos nossos sujeitos (quadro 3) conseguiram argumentar suas respostas, trazendo não só uma resposta correta, mas também uma justificativa com elementos científicos que sustentam sua veracidade.

Alguns alunos conseguiram apresentar uma resposta correta para a questão, no entanto, ao apresentar sua justificativa, recorreram ao senso comum, ou seja, aqueles conhecimentos construídos durante a sua vida, sejam eles na esfera familiar, escolar ou social. Tal categoria foi estabelecida levando em consideração que os sujeitos utilizaram de conhecimentos do seu dia a dia para resolver o desafio proposto. Essa categoria está apresentada no quadro 4.

Quadro 4 - Categoria 2: Justificativas com base em conhecimento do senso comum

\begin{tabular}{|c|l|}
\hline Sujeitos & \multicolumn{1}{c|}{ Descrição } \\
\hline S4 & $\begin{array}{l}\text { Água de torneira por estar gelada refresca e alivia a coceira diminui o inchaço e está } \\
\text { mais acessível. }\end{array}$ \\
\hline S6 & $\begin{array}{l}\text { Leite de magnésio e água de torneira pois eles diminuem a alergia e é bom para o } \\
\text { consumo. }\end{array}$ \\
\hline S7 & $\begin{array}{l}\text { Leite de magnésio, pois ele é próprio para o consumo e ele pode ser tomado em doses } \\
\text { aliviando a ardência. }\end{array}$ \\
\hline S11 & $\begin{array}{l}\text { Eu colocaria o leite de magnésio, tomaria algumas doses ou até mesmo passaria ele no } \\
\text { lugar atingindo, além de ele servir como laxante e ser próprio para o consumo. }\end{array}$ \\
\hline S12 & Primeiramente a água em abundância e depois com o detergente ou leite de magnésio. \\
\hline S14 & Leite de magnésio, porque ele é uma base e faz bem para a saúde. \\
\hline S18 & $\begin{array}{l}\text { Leite de magnésio, pois como ele diminui a queimação da azia então além de aliviar a } \\
\text { dor aliviaria a irritação. }\end{array}$ \\
\hline
\end{tabular}

Fonte: Os autores 2019.

Essa categoria reúne concepções apresentadas por 7 alunos, o que totaliza $32 \%$ dos sujeitos participantes da atividade proposta.

O leite de "magnésio", mais conhecido como leite de magnésia, apontado por seis sujeitos é utilizado popularmente contra a má digestão, azia e também como laxante, muito popular no Brasil. O bicarbonato de sódio utilizado, citado por dois alunos em suas 
justificativas, também é propício para o consumo, podendo ser usado no combate a acidez estomacal.

O sujeito S18 aponta o leite de magnésia, justificando que ele diminui a azia e, também no respectivo caso poderia aliviar a irritação. O sujeito S14 tem a mesma linha de raciocínio, pois afirma que ele faz bem para a saúde. Ambas as respostas podem ser associadas ao cotidiano desses alunos.

O sujeito S4 justificou o uso da água de torneira por estar mais acessível. Apesar dos alunos discorrerem suas respostas, não encontramos nos mesmos elementos científicos que as justificassem como corretas, por isso as classificamos como pertencentes ao senso comum.

Assim, dos vinte e dois alunos participantes da pesquisa, dezoito conseguiram descrever uma resposta com uma justificativa, ainda que dessas apenas onze apresentassem conceitos científicos em suas argumentações. Podemos dizer que $82 \%$ de nossa amostra apresentou bons resultados com relação às habilidades de escrever e argumentar, o que consideramos um excelente resultado, visto que são alunos de Ensino Médio e não estão acostumados às atividades como estas, na qual é preciso argumentar cientificamente.

Já os $18 \%$ restantes dos sujeitos pesquisados, ou seja, quatro alunos, não apresentaram respostas coerentes. Quanto às justificativas, os sujeitos (S13) e (S15) ao apontarem o "limpaforno", não se atentaram para o fato desse material se tratar de uma base forte e, por esse motivo, não aliviaria a coceira, mas sim potencializaria a irritação. Os sujeitos (S3) e (S16) apresentaram justificativas confusas e incoerentes com as observações que fizeram em grupo após a realização do experimento. As respostas desses alunos estão descritas no quadro 5.

\begin{tabular}{|c|l|}
\multicolumn{2}{|c|}{ Quadro 5 - Categoria 3: Sem Justificativas e/ou Justificativas incoerentes } \\
\hline Sujeitos & \multicolumn{1}{c|}{ Descrição } \\
\hline S3 & Eu usaria água de torneira por estar perto do pH neutro. \\
\hline S13 & $\begin{array}{l}\text { Usaria limpa forno ou bicarbonato, pois o pH parece maior, ou seja, a ação contra o } \\
\text { ácido vai ser maior e mais rápida. }\end{array}$ \\
\hline S15 & $\begin{array}{l}\text { Eu poderia usar bicarbonato de sódio, limpa forno, hidróxido de alumínio, leite de } \\
\text { magnésio, qualquer um deles iria ajudar a diminuição da irritação pois todos são bases, } \\
\text { então iriam se igualar ao ácido e parar de irritar. }\end{array}$ \\
\hline S16 & \begin{tabular}{l} 
Eu usaria o detergente pois ele é base ou o hidróxido de magnésio. \\
\hline
\end{tabular}
\end{tabular}

Fonte: Os autores 2019.

As respostas e justificativas apresentadas pelos participantes da pesquisa indicam que o resultado desse estudo foi bastante satisfatório, tendo em vista que a maioria dos alunos compreendeu o experimento em pauta e soube responder à questão referente à aplicação do 
conhecimento, apresentando argumentos interessantes, sejam eles relacionados ao conteúdo químico discutido ou situações do cotidiano.

\section{CONSIDERAÇões FinaIS}

Nosso trabalho objetivou verificar junto a uma turma do segundo ano do Ensino Médio (EM) de uma escola pública de Maringá-PR, o potencial de uma atividade experimental investigativa para abordar o tema ácidos e bases. Utilizamos os referenciais do ensino por investigação para fundamentar a atividade.

Podemos inferir que o experimento investigativo desenvolvido favoreceu o entendimento conceitual dos alunos sobre os ácidos e bases, permitindo a interação entre os participantes, bem como a elaboração de argumentos no momento de comunicarem seus resultados de aprendizagem.

Diante da realidade e do contexto escolar, acreditamos que o professor tem um papel fundamental entre o aluno e o conhecimento, o de mediador. As ações pedagógicas do docente podem favorecer a apropriação desse conhecimento e as formas de pensar e agir dos estudantes frente ao conhecimento, a partir do desenvolvimento de trabalhos experimentais com abordagem investigativa. Experimentos investigativos possibilitam a participação ativa dos alunos por meio de discussões, observações entre outras, características fundamentais no processo de construção de conhecimentos científicos.

\section{REFERÊNCIAS}

BOGDAN, R.; BIKLEN, S. Investigação qualitativa em educação: uma introdução à teoria e aos métodos. Portugal: Porto, 1994.

CARVALHO, A. M. P. Fundamentos teóricos e metodológicos do Ensino por Investigação. Revista Brasileira de Pesquisa em Educação em Ciências. Belo Horizonte, v. 18, n. 03, p. 765-794, 2018.

CARVALHO, A. M. P. O ensino de ciências e a proposição de sequências de ensino investigativas. In: CARVALHO, A. M. P. (Org.). Ensino de Ciências por Investigação: condições para implementação em sala de aula. São Paulo: Cengage Learning, 2013, p. 1-20.

COSTA, R. C. Construção do conhecimento científico segundo algumas contribuições da epistemologia de Bachelard. In: MORAES, Roque (Org). Construtivismo e ensino de ciências: reflexões epistemológicas e metodológicas. Porto Alegre: EDIPUCRS, 2000.

FERREIRA, L. H.; HARTWIG, D. R.; OLIVEIRA, R. C. Ensino experimental de química: uma abordagem investigativa contextualizada. Química Nova na Escola. São Paulo, v. 32, n. 02, p. 101-106, 2010. 
GONÇALVES, F. P; BRITO, M. A. Experimentação na educação em Química: fundamentos, propostas e reflexões. Florianópolis: Ed. da UFSC, 2014.

KASSEBOEHMER, A. C; HARTWIG, D. R; FERREIRA, L. H. Contém Química 2: pensar, fazer e aprender pelo método investigativo. São Carlos: Pedro \& João Editores, 2015.

MONTEIRO, P. C. A experimentação investigativa: um estudo com licenciandos em Química. 2018. 165f. Maringá: Tese (Doutorado em Ensino de Ciências) - Universidade Estadual de Maringá, Maringá, 2018. Disponível em: https://sucupira. capes.gov.br/ sucupira/public/consultas/coleta/trabalhoConclusao/viewTrabalhoConclusao.jsf?popup true\&id_trabalho=7198502. Acesso em: 09/04/2019.

MONTEIRO, P. C; RODRIGUES, M. A; SANTIN FILHO, O. Experimentos com abordagem investigativa propostos por licenciandos em Química. In: ENCONTRO NACIONAL DE PESQUISA EM EDUCAÇÃO EM CIÊNCIAS, 11., 2017, Florianópolis. Anais... Florianópolis: Abrapec, 2017. Disponível em: http://www.abrapecnet.org.br/enpec/xienpec/anais/resumos/R1530-1.pdf. Acesso em: 19/03/2019.

MORAES, R; GALIAZZI, M. C. Análise textual discursiva. Ijuí: Ed. Unijuí, 2007.

OLIVEIRA, C. M. A. O que se fala e se escreve nas aulas de Ciências? In: CARVALHO, A. M. P. (Org.). Ensino de Ciências por Investigação: condições para implementação em sala de aula. São Paulo: Cengage Learning, 2013, p. 63-75.

PAVÃO, A. C; FREITAS, D (Org.). Quanta ciência há no ensino de ciências. São Carlos: EdufSCAR, 2011.

ROSITO, B. A. O ensino de Ciências e a experimentação. In: MORAES, R. (Org.).

Construtivismo e ensino de ciências: reflexões epistemológicas e metodológicas. Porto Alegre: EDIPUCRS, 2000.

SANTANA, E.; SILVA, E. (Org.). Tópicos em Ensino de Química. São Carlos: Pedro \& João Editores, 2014.

SANTOS, W. L. P; MÓL, G. S. Química \& Sociedade: PEQUIS - projeto de ensino de química e sociedade: ensino médio. São Paulo: Nova Geração, 2005.

SASSERON, L. H. Interações discursivas e investigação em sala de aula: o papel do professor. In: CARVALHO, A. M. P. (Org.). Ensino de Ciências por Investigação: condições para implementação em sala de aula. São Paulo: Cengage Learning, 2013, p. 4161.

SASSERON, L. H., MACHADO, V. F., Alfabetização científica na prática: inovando a forma de ensinar física. Editora livraria da fisica, $1^{\mathrm{a}}$. ed. 2017.

SILVA, L. H. A.; ZANON, L. B. A experimentação no ensino de ciências. In: SCHNETZLER, R. P.; ARAGÃO, R. M. R. (Org.). Ensino de ciências: fundamentos e abordagens. Campinas: R. Vieira Gráfica e Editora Ltda., 2000. p. 120-153.

SILVA, M. L. O uso de materiais de baixo custo para experimentação nas aulas de densidade e pressão hidrostática. Revista Prática Docente. Confresa: MT, v. 2, n. 1, p. 62-70, jan/jun 
2017. Disponível em: http://periodicos.cfs.ifmt.edu.br/periodicos/index.php/rpd/article/ view/47/23 Acesso em: 11/04/2019.

SUART, R. C. A experimentação no ensino de Química: conhecimentos e caminhos. In: SANTANA, E.; SILVA, E. (Org.). Tópicos em Ensino de Química. São Carlos: Pedro \& João Editores, 2014. p. 63-88.

Recebido em:11 de abril de 2019.

Aprovado em: 18 de junho de 2019. 